\title{
Influence of nitrogen content on the structural, mechanical and electrical properties of TiN thin films
}

\author{
F. Vaz ${ }^{\text {a }}$ J. Ferreira ${ }^{\text {a }}$, E. Ribeiro ${ }^{\text {a }}$, L. Rebouta ${ }^{\text {a }}$, S. Lanceros-Méndez ${ }^{\mathrm{a}}$, J.A. Mendes $^{\mathrm{a}}$, E. Alves ${ }^{\mathrm{b}, *}$,

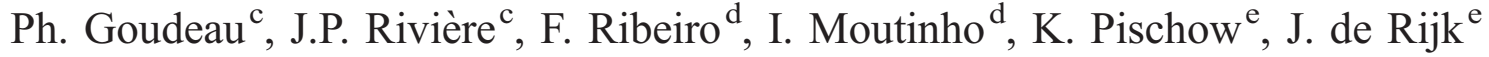 \\ ${ }^{a}$ Universidade do Minho, Department Física, Campus Azurém, 4800-058 Guimarães, Portugal \\ ${ }^{\mathrm{b}}$ ITN, Departamento de Física, E.N.10, 2686-953 Sacavém, Portugal \\ ${ }^{\mathrm{c}}$ Université de Poitiers, Laboratoire de Métallurgie Physique, 86960 Futuroscope, France \\ ${ }^{\mathrm{d}}$ Universidade do Minho, Dept. Electr. Industrial, Azurém, 4800-058 Guimarães, Portugal \\ e Savcor Coatings Oy, Insinöörinkatu 7, 50100 Mikkeli, Finland
}

Received 27 November 2003; accepted in revised form 30 January 2004

Available online 6 May 2004

\begin{abstract}
This paper reports on the preparation of $\mathrm{TiN}_{x}$ thin films by d.c. reactive magnetron sputtering. The coating thickness ranged from 1.7 to $4.2 \mu \mathrm{m}$ and the nitrogen content varied between 0 and 55 at.\%. X-Ray diffraction showed the development of the hexagonal $\alpha$-Ti phase, with strong [002] orientation for low nitrogen contents, where the $\mathrm{N}$ atoms fit into octahedral sites in the Ti lattice as the amount of nitrogen is increased. For nitrogen contents of 20 and 30 at.\%, the $\varepsilon-\mathrm{Ti}_{2} \mathrm{~N}$ phase appears with [200] orientation. With further increasing the nitrogen content, the $\delta$-TiN phase becomes dominant. The electrical resistivity of the different compositions reproduces this phase behavior. The hardness of the samples varied from approximately $8 \mathrm{GPa}$ for pure titanium up to $27 \mathrm{GPa}$ for a nitrogen content of 30 at. $\%$, followed by a slight decrease at the highest contents. A similar increase of stresses with nitrogen is observed. Structure and composition with the consequent changes in crystalline phases and the lattice distortion were found to be crucial in the evolution of the mechanical properties. (C) 2004 Elsevier B.V. All rights reserved.
\end{abstract}

Keywords: Titanium nitride; Nitrides; Structural properties; Sputtering; Resistivity

\section{Introduction}

The continuous progress in surface and thin film technology is largely connected to the adjustment of structural and chemical film properties to actual applications. The resulting demands for increased sophistication of thin film structures can, in general, only be achieved by an appropriate choice and precise control over the parameters governing the deposition process. Besides the deposition parameters related with the film forming particle flux, stoichiometry of the deposited films has to be considered as one of the most essential parameter for determining the microstructural properties and chemical binding conditions of the growing film. In this respect, thin films elaborated through physical vapor deposition (PVD) processes are well known to exhibit a microstructure that is strongly dependent on these stoichiometric features $[1,2]$.

\footnotetext{
* Corresponding author. Tel.: +351-21-9946086; fax: +351-21-991525.

E-mail address: ealves@itn.mces.pt (E. Alves).
}

In recent years there has been an increasing interest in elucidating the mechanisms which lead to thin-film property modification caused by the so-called substoichiometric condition [3-8]. Much of our understanding of these structures and the relationships to their formation mechanism has come from the study of both computer simulation and theoretical methods [3-11]. This study is of major importance since a detailed understanding of the processes is fundamental for the preparation of new materials and novel devices that exhibit improved physical properties [12-14].

Stoichiometric titanium nitride (TiN) is actually one of the most important technological coating materials, not only because of its excellent tribological properties, but also due to its good chemical stability. It is certainly, in tribological terms, the most explored PVD hard thin film material and most extensively used in industry. It is used in a wide range of applications, which vary from protective material for machine parts and cutting tools [15] to diffusion barriers in semiconductor technology [16]. In the past, properties of substoichiometric titanium nitride $\left(\mathrm{TiN}_{x}\right)$ have been studied 
by comparably few researchers considering only basic properties such as hardness, phase composition or lattice distortion [17-23]. All these investigations focused mainly on the $\delta$-TiN-phase, whereas little attention was paid to the properties of the nitrogen containing $\alpha-\mathrm{Ti}$ phase. In this paper, we investigate the structural, physical and mechanical properties of substoichiometric $\mathrm{TiN}_{x}$ coatings aiming an accurate understanding of its evolution as a function of the increasing nitrogen content.

\section{Experimental details}

\subsection{Sample materials}

The $\operatorname{TiN}_{x}$ samples were deposited by reactive d.c. magnetron sputtering, from a high purity $\mathrm{Ti}$ target $\left(200 \times 100 \times 6 \mathrm{~mm}^{3}\right)$ onto polished high-speed steel (AISI M2), stainless steel (AISI M316) and single crystal silicon substrates. The depositions were carried out in a 'homemade' magnetron sputtering apparatus, in an $\mathrm{Ar} / \mathrm{N}_{2}$ atmosphere [24]. This deposition system consists of two vertically opposed rectangular magnetrons (unbalanced of type 2 [25]) in a closed field configuration. Primary vacuum in the deposition chamber was achieved using two rotary pumps $\left(8.5\right.$ and $\left.12 \mathrm{~m}^{3} / \mathrm{h}\right)$. The secondary vacuum was obtained using two turbomoleculares pumps of 190 and $400 \mathrm{l} / \mathrm{s}$. The substrates were ex situ ultrasonically cleaned and in situ sputter etched for $15 \mathrm{~min}$. in a pure $\mathrm{Ar}$ atmosphere, using a pulsed power supply: $I \approx 0.35 \mathrm{~A}$; $V \approx 300 \mathrm{~V} ; f=200 \mathrm{kHz}$. A pure titanium adhesion layer (d.c. power source: $I=1 \mathrm{~A}, \mathrm{~V} \approx 360 \mathrm{~V} ; V_{\text {bias }}=-70 \mathrm{~V}$; $T_{s} \approx 250{ }^{\circ} \mathrm{C}$ ) with a thickness of $\sim 0.40 \mu \mathrm{m}$ was deposited on the substrate prior to the coating deposition. A summary of all the main deposition parameters is illustrated in Table 1.

\subsection{Characterization techniques}

An average number of five ball cratering experiments were carried out in each sample in order to determine its thickness. The composition and homogeneity of the films was assessed by RBS and ERDA. RBS studies were performed with a $1 \mathrm{~mm}$ diameter collimated beam of ${ }^{4} \mathrm{He}^{+}$ or ${ }^{1} \mathrm{H}^{+}$ions. The backscattered particles were detected at $140^{\circ}$ and close to $180^{\circ}$, with respect to the beam direction using silicon surface barrier detectors with resolutions of 13 $\mathrm{keV}$ and $16 \mathrm{keV}$, respectively. The results were analyzed with the NDF code [26].

$\mathrm{X}$-Ray diffraction (XRD) patterns were recorded in a SIEMENS D5000 diffractometer $\left(\mathrm{Cu} \mathrm{K}_{\alpha}\right.$ radiation) in $\theta-2 \theta$ (Bragg-Brentano) mode, equipped with a secondary graphite monochromator to avoid parasitic intensities (fluorescence) of $\mathrm{Fe}$ and $\mathrm{Cr}$ atoms from steel substrates. The resistivity of the films was measured by the van der Pauw method [27] at room temperature, using silver paint contacts in the films deposited on Si substrates.

Residual stresses, $\sigma_{r}$, were calculated using the Stoney equation [28], from substrate curvature radii, measured before and after coating deposition by scanning the sample surface with a laser beam and measuring the reflected light intensity (laser triangulation). The deflections of the surface used for the determination of the radius of curvature were measured with accuracy better than $1 \mu \mathrm{m}$. The parabolic deflections correspond to orthogonal directions in the film surface plane. For more detailed information on the procedure see Ref. [29].

Coating hardness was determined from the loading and unloading curves, carried out with an ultra low load depth sensing nanoindenter-Nano Instruments Nanoindenter II [30], equipped with a Berkovich diamond indenter and operating at a constant displacement rate of $5 \mathrm{~nm} / \mathrm{s}$. An indentation depth of $100 \mathrm{~nm}$ was used for every measurement. This indentation depth was kept within the recommended value of roughly $10-20 \%$ of the film thickness to avoid substrate effect [31]. The unload segment is load controlled with an unloading rate equal to $50 \%$ of the loading rate, at the end of the previous load segment. The unloading continues until $90 \%$ of the previous load has been removed from the indenter. The elastic modulus was estimated by the slope of the initial portion of the unloading curve, adopting

Table 1

Deposition parameters during sample preparation

\begin{tabular}{|c|c|}
\hline Substrate temperature & $250{ }^{\circ} \mathrm{C}$ \\
\hline Rotational speed & $7 \mathrm{rot} . / \mathrm{min}$ \\
\hline Target to substrate distance & $70 \mathrm{~mm}$ \\
\hline d.c. bias voltage & $-70 \mathrm{~V}$ \\
\hline Ion current density at the substrate [24] & $1.5 \mathrm{E} 20$ ions $^{-1} \mathrm{~m}^{-2}$ \\
\hline Total pressure & $\approx 4 \times 10^{-1} \mathrm{~Pa}$ \\
\hline Base pressure & $\approx 1 \times 10^{-4} \mathrm{~Pa}$ \\
\hline $\mathrm{N}_{2}$ flow & 0 to $8 \mathrm{sccm}$ \\
\hline Ar flow & $23 \mathrm{sccm}$ \\
\hline $\mathrm{N}_{2}$ partial pressure & 0 to $3 \times 10^{-2} \mathrm{~Pa}$ \\
\hline d.c. current density at the $\mathrm{Ti}$ target & $1 \times 10^{+2} \mathrm{~A} / \mathrm{m}^{2}(V \approx 400 \mathrm{~V})$ \\
\hline
\end{tabular}


Sneddon's flat-ended cylinder punch model [32]. Hardness values were obtained from the average of 20 measurements at different positions.

\section{Results and discussion}

\subsection{Characterization of the as deposited samples}

The dependence of coating composition on nitrogen flow during the process was measured by RBS. Fig. 1 illustrated the RBS result obtained for one of the samples. No oxygen and argon were detected in the as-deposited samples, which mean that their content is less than $\sim 2$ at.\%. The nitrogen content of the films first rises slowly from 0 to 8 at.\% upon increasing the nitrogen flow from 0 to $3 \mathrm{sccm}$, Fig. 2 . Further increase of the nitrogen flow ratio leads to a steeper increase of the coating nitrogen content up to 50 at.\%, for $6.5 \mathrm{sccm}$, which corresponds to the stoichiometric situation, TiN. For higher flows $(\geq 6.5 \mathrm{sccm})$, the nitrogen content rises only slightly.

\subsection{Structural characterization}

Previous investigations of substoichiometric titanium nitride films deposited by different PVD techniques, have shown that increasing nitrogen flows and so its partial pressure during the deposition process leads to gradually higher nitrogen contents in the films [18,21]. The increase in the $\mathrm{N}$ content that is observed here for nitrogen contents up to 45 at.\%, was also evidenced by other authors [21], and can be related to both the continuous insertion of nitrogen within the crystalline lattice of $\mathrm{Ti}$, as well as to the operation conditions that consist in low quantities of nitrogen gas flows and thus not severe poisoning of the target $[18,21,33]$. The $\varepsilon-\mathrm{Ti}_{2} \mathrm{~N}$ phase, a line compound only existing for very

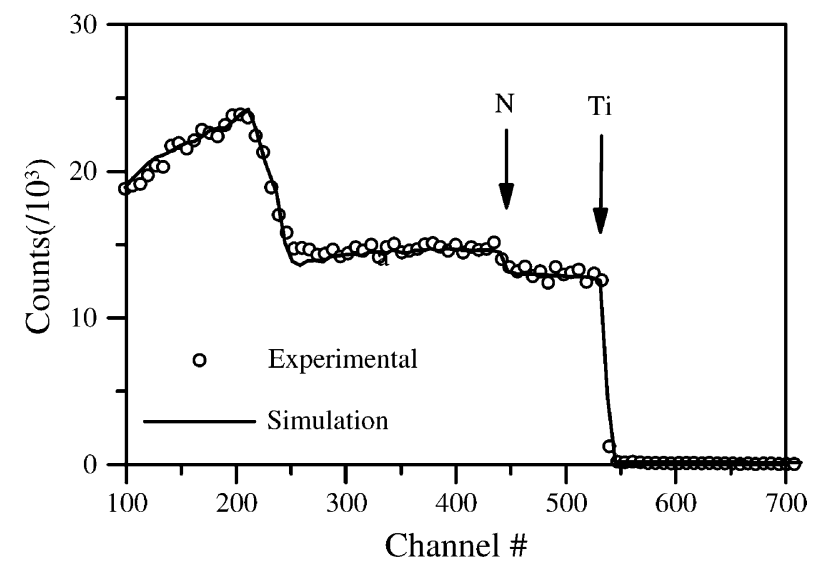

Fig. 1. RBS spectra obtained with a $1.5 \mathrm{MeV}^{1} \mathrm{H}^{+}$beam for a film grown with a gas flow of $5 \mathrm{sccm}$ and a bias voltage of $-50 \mathrm{~V}$. The continuous line indicates the best fit derived from the NDF simulation. The barrier around channel 240 is due to signals from the substrate.

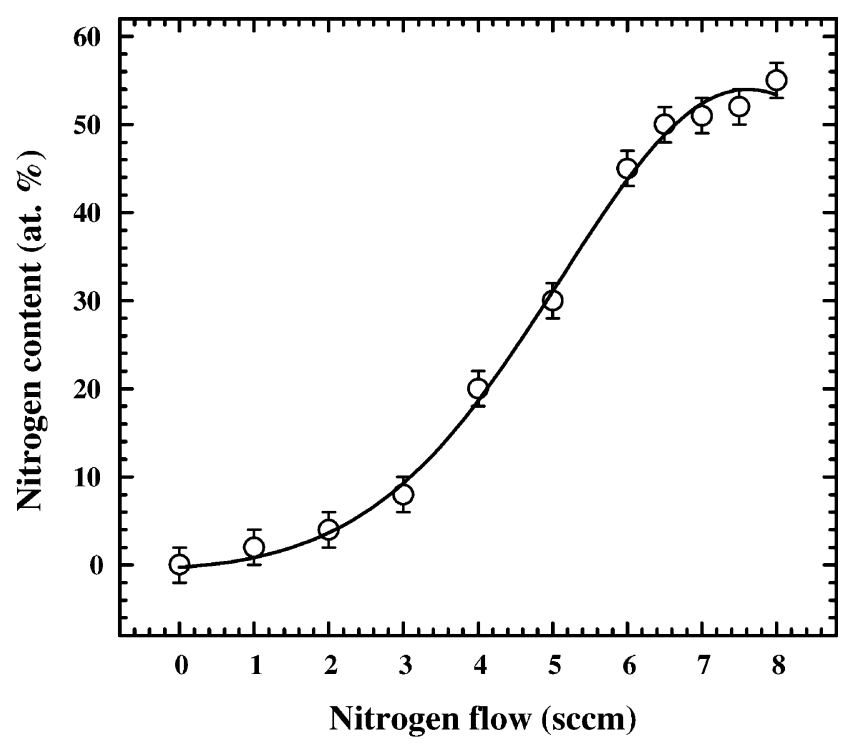

Fig. 2. Plot of the nitrogen content as a function of the nitrogen gas flow.

specific titanium to nitrogen ratio [34-36], crystallizes in the 'anti-rutile' $\left(\mathrm{P}_{2} / \mathrm{mnm}\right)$ structure, which consists of a bcc Ti lattice, with $\mathrm{N}$ atoms filling one-half of the available octahedral sites (rather than all of the octahedral sites as in TiN). As $\mathrm{N}$ is added to Ti, Ti transforms from the hcp $\alpha-\mathrm{Ti}$ phase to the bcc $\varepsilon-\mathrm{Ti}_{2} \mathrm{~N}$ phase, and finally to the fcc $\delta$-TiN phase. Although the appearance of this $\varepsilon-\mathrm{Ti}_{2} \mathrm{~N}$ phase is not clearly visible due to the influence of the diffraction peak corresponding to the $\{111\}$ planes of $\delta$-TiN phase, it seems nevertheless to be particularly evident for samples with 20 and 30 at. $\% \mathrm{~N}$ (as expected from the phase diagram [3436]). A closer look to the XRD diffraction patterns, Fig. 3, reveals the development of the hexagonal $\alpha$-Ti phase with strong [002] orientation for low nitrogen contents. The diffraction peaks are progressively shifted towards lower diffraction angles as the $\mathrm{N}$ content increases. For nitrogen contents of 20 and 30 at. $\%$, the $\varepsilon-\mathrm{Ti}_{2} \mathrm{~N}$ phase appears with a [200] orientation. Furthermore, and although it does not seem clearly visible, the $\delta$-TiN phase might be already developing in this range of nitrogen contents. The broad diffraction lines do not allow an easy conclusion concerning the exact nature of the crystalline compounds present in the diffractograms, though the phase diagram predicts only the $\varepsilon-\mathrm{Ti}_{2} \mathrm{~N}$ phase as well as the $\alpha-\mathrm{Ti}$.

The titanium-nitrogen phase diagram is complex, but basically Ti crystal is said to be an 'interstitial' crystal where $\mathrm{N}$ atoms fit into the gaps in the Ti structure. This structure evolves from hexagonal $\alpha$-Ti (space group P63/mmc), to face-centred-cubic $\delta$-TiN (space group Fm-3 m), the $\mathrm{N}$ atoms being into octahedral sites of the Ti lattice as the amount of nitrogen is increased. The $\alpha$-Ti lattice is able to accept small amounts of nitrogen at octahedral sites [37], but since PVD is a thermodynamically non-equilibrium process, the $\alpha$-Ti lattice may be forced to accept more nitrogen atoms due to hindered mobility of the deposited 


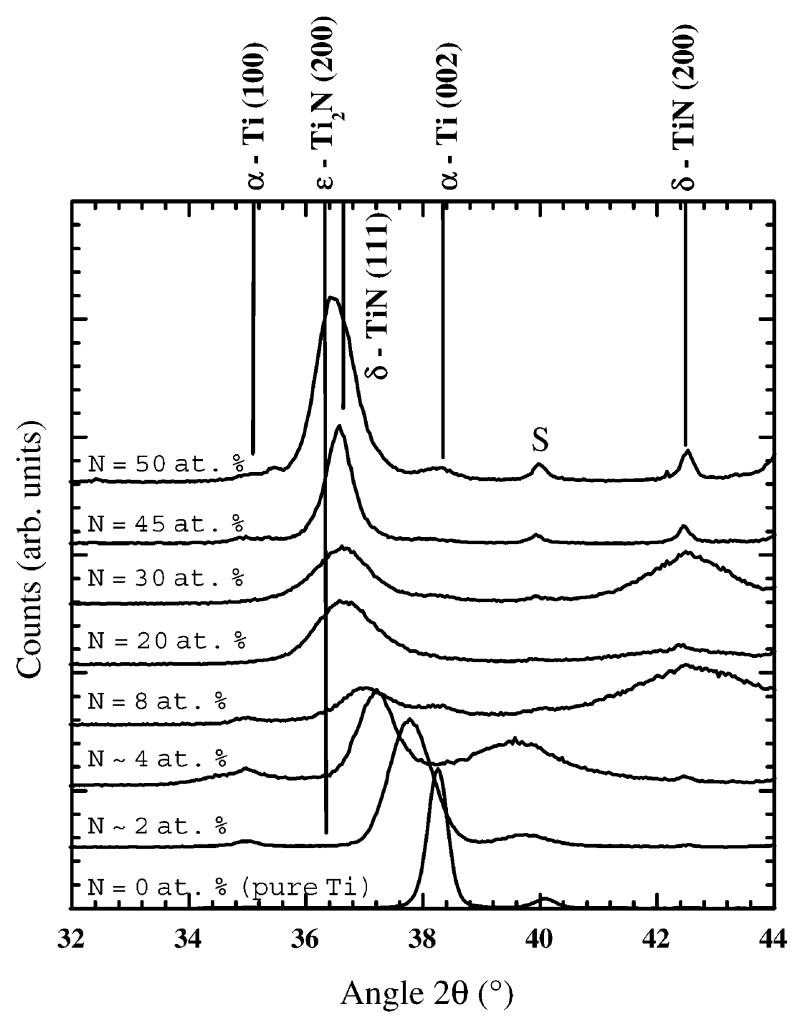

Fig. 3. Evolution of the XRD patterns of the films as a function of nitrogen contents. S corresponds to the diffraction lines of the substrate.

particles [19]. Therefore an oversaturated metastable solution of nitrogen in titanium is formed for the lower $\mathrm{N}$ contents. The shift in the diffraction lines revealed by Fig. 3 is thus a consequence of this progressive increase of $\mathrm{N}$ interstitials in octahedral $\alpha$-Ti sites, which causes lattice distortion. At intermediate concentrations of $\mathrm{N}$ between 20 and 30 at.\%, the diffraction peaks become quite broad indicating that grains of very small sizes and large micro strains are developed. This tendency towards smaller grain sizes is typical of highly saturated metal-metalloid alloys and can be described by the Gibbs-Thomson equation [38]. Oversaturation under non-equilibrium conditions often leads to vanishing lattice order [17], inducing an increase in the deposition rates. This is the case here where an increase in this parameter is observed for the films with the lowest $\mathrm{N}$ concentration ( $<10$ at.\%) (Fig. 4). As the stoichiometric condition becomes closer and thus approaching the equilibrium condition, the deposition rates decrease as illustrated in Fig. 4. The reason for this decrease in the deposition rate is that the reactive gas can react with Ti target to form a nitrided compound layer at its surface, which reduces the metal sputtering yield. This is partly due to the poor sputtering capability of nitrogen upon replacing argon and partly from the target poisoning effects (induced by the increasing amount of nitrogen in the chamber) where the sputtering yield for nitride is much smaller than the metal, and partly that these compounds have higher secondary electron emission yields than metal targets $[18,21,33]$. With further increase of nitrogen flow, the deposition rate is almost unchanged and very low.

The investigation of the coating morphology by SEM showed a columnar-type structure for all films, lying in the transition zone between $\mathrm{T}$ and $\mathrm{I}$ zones of Thornton Model [39]. A closer look at the different cross-section images revealed a clear tendency for the thickening of the columns as the $\mathrm{N}$ content increases, Fig. 5. Plan view observation also revealed some changes, namely in what concerns the surfaces roughness, which seems to decrease with the increase in the $\mathrm{N}$ content. The decrease in grain size explains the observed densification of the initially columnar coating structure as well as the smoothening of the surface.

\subsection{Resistivity}

The electrical resistivity or a material is mainly determined by the intrinsic properties, defects and temperature (thermal vibrations). By varying the $\mathrm{N}$ content and performing experiments at room temperature, phase composition, microstructure and defects (dislocations, impurities and grain boundaries) become determinant parameters.

The electrical resistivity for pure Ti ( $\rho$ approx. $60 \mu \Omega$ $\mathrm{cm}$ ) increases heavily by increasing $\mathrm{N}$ content up to a maximum of $\rho \sim 190 \mu \Omega \mathrm{cm}$ at concentrations between 2 and 8 at.\%. Further, increasing the nitrogen content reduces progressively the resistivity to values below those obtained for pure $\mathrm{Ti}$ ( $\rho$ approx. $40 \mu \Omega \mathrm{cm}$ for $\mathrm{N}>50$ at.\%) (Fig. 6). The initial rapid increase of the electrical resistivity for increasing $\mathrm{N}$ concentration up to $\sim 8$ at. $\%$ is to be ascribed to the increase of impurity defects: for low concentrations, the $\mathrm{N}$ atoms occupy interstitial positions into the hexagonal $\alpha$-Ti structure. This fact is supported by the broadening of the diffraction peaks (Fig. 3), indicating smaller grains and large microstrains that accompany vanishing lattice order and increase in the deposition rates (Fig. 4).

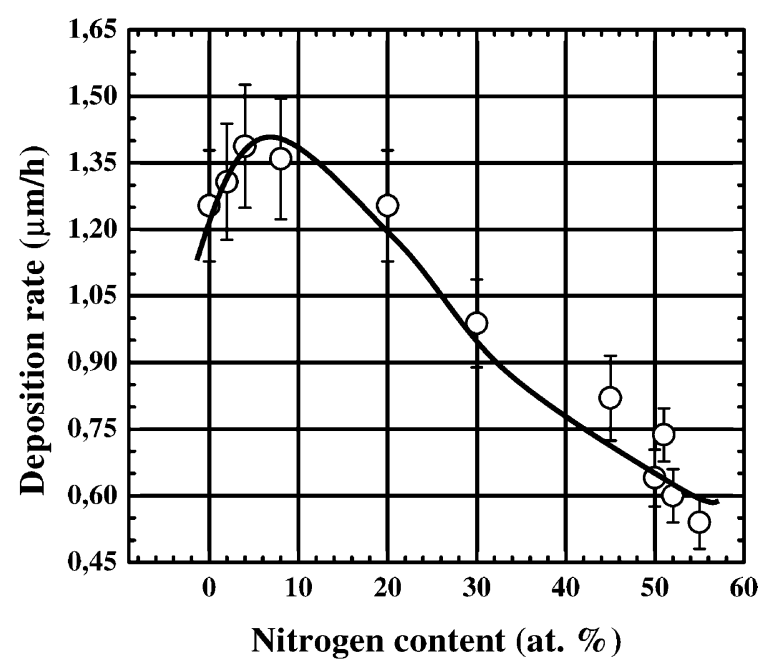

Fig. 4. Deposition rate of the $\operatorname{TiN}_{x}$ films as a function of the nitrogen content. 

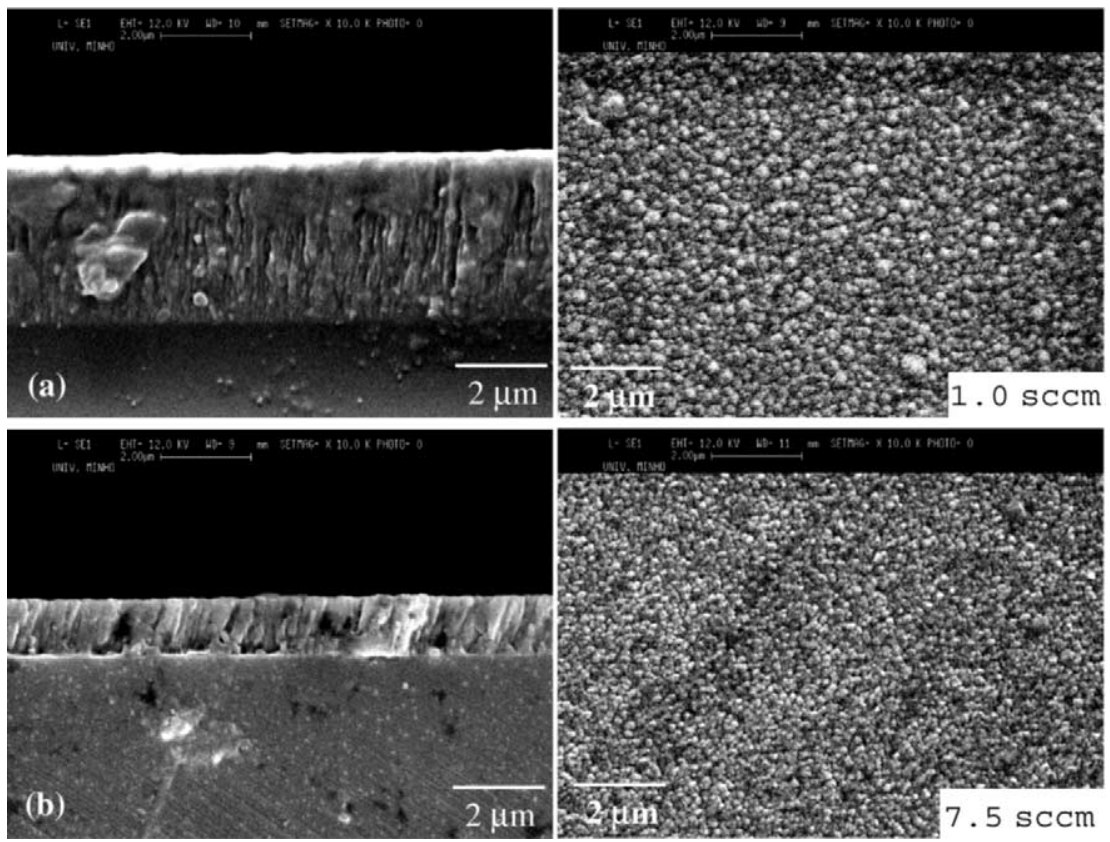

Fig. 5. SEM cross-section and plan view images, showing the morphological changes in $\mathrm{TiN}_{x}$ films for different nitrogen flow rates: (a) 1 sccm ( 2 at. $\%$ N); (b) $7.5 \mathrm{sccm}(52$ at. $\% \mathrm{~N})$.

Further, small amounts of $\mathrm{N}$ can occupy octahedral sites of the Ti lattice, as indicated by the shift of the diffraction lines in Fig. 3. This leads to the progressive formation of an energetically more favorable lattice configuration $\left(\varepsilon-\mathrm{Ti}_{2} \mathrm{~N}\right)$ by increasing $\mathrm{N}$ concentrations. Phase coexistence rules, thus, the behavior of the resistivity at concentrations approximately 8 at.\% (maximum of resistivity). By further increasing of the $\mathrm{N}$ content, the energetically more favorable lattice configuration of the $\varepsilon-\mathrm{Ti}_{2} \mathrm{~N}$ becomes progressively dominant, with the consequent decrease of the resistivity by reducing the amount of interstitial impurity defects and the phase coexistence (Figs. 3 and 4).

Morphology characterization revealed a thickening of the columns and a decrease of the grain size with increasing $\mathrm{N}$

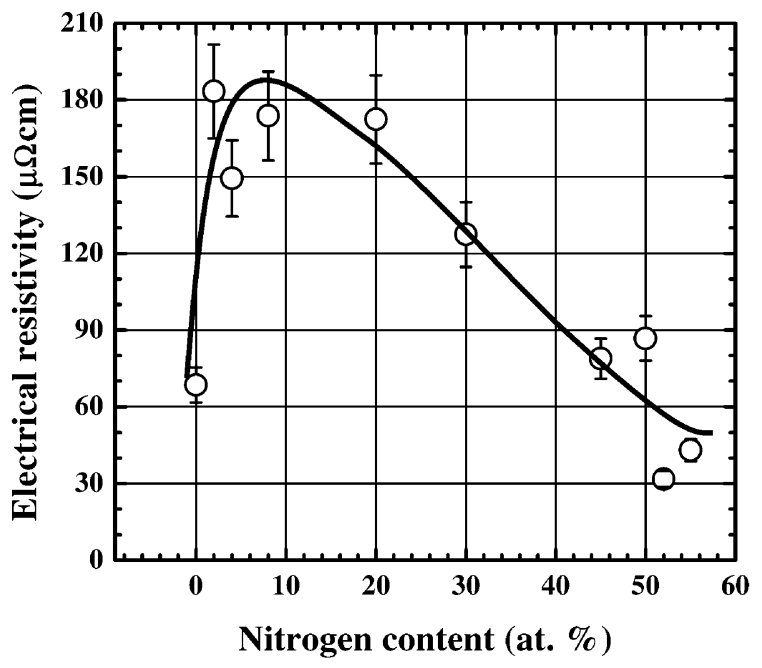

Fig. 6. Electric resistivity, $\rho$, of $\mathrm{TiN}_{x}$ films as a function of nitrogen content. content. The fact that resistivity increases for $\mathrm{N}$ concentrations up to 8 at. $\%$ and decreases for concentrations higher than this indicates that morphology features are not a parameter as relevant as the upper mentioned structural variations.

\subsection{Mechanical properties: hardness and residual stresses}

With increasing nitrogen content the films become harder, where the hardness value varies from approximately $8 \mathrm{GPa}$ for pure titanium, up to $27 \mathrm{GPa}$ for an optimal nitrogen content of 30 at.\% (Fig. 7). It is worth noticing that the films exhibit almost a constant hardness value of

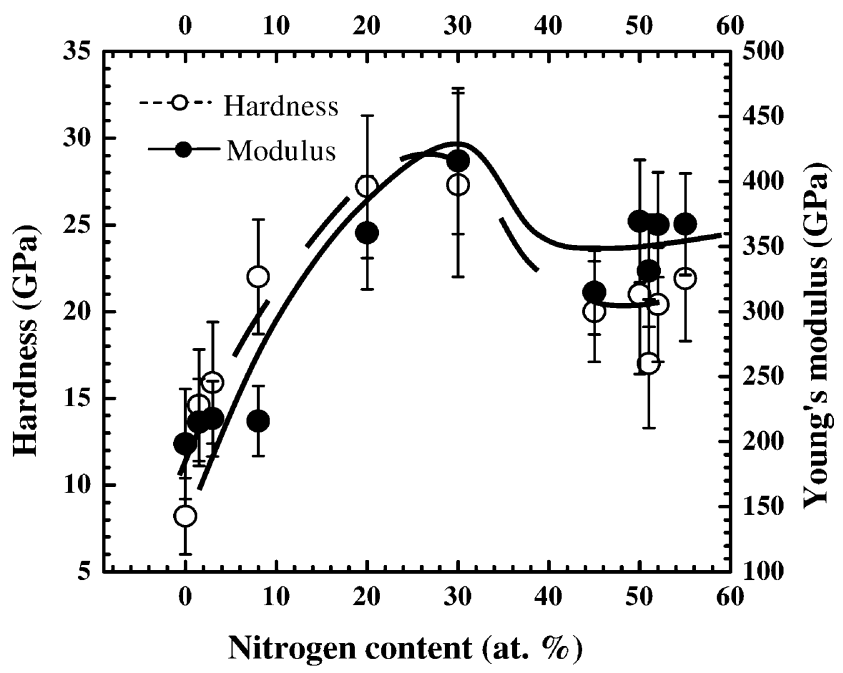

Fig. 7. Hardness and Young's modulus of sputtered $\mathrm{TiN}_{x}$ films as a function of the nitrogen content. 
approximately $20 \mathrm{GPa}$ within the range of 45 and 55 at. $\% \mathrm{~N}$ including stoichiometric TiN.

Two main factors may contribute for this increasing hardness of the $\mathrm{TiN}_{x}$ films: (i) structure/composition (affected by the processing conditions) and; (ii) the lattice distortions that are responsible for a reducing in dislocations motion $[19,36,40]$. In terms of the structural features, it is worth notice that the two harder samples are those that seem to reveal the presence of the $\varepsilon-\mathrm{Ti}_{2} \mathrm{~N}$ phase, corresponding to 20 and 30 at.\% N (see Fig. 3). The existence of this phase has been claimed to act as a hardening factor [41-44]. This effect is presumed to be in the form of either: (i) a precipitation nuclei, which rarely exhibit their own diffraction pattern and in such a case precipitation hardening effect is considered or; (ii) very fine grains, which is probably the case here, taking in consideration the large broadening of the diffraction peaks of samples with 20 and 30 at.\% N. The initial hardening for the lowest $\mathrm{N}$ contents is a consequence of the distortion in the $\alpha$-Ti lattice, due to $\mathrm{N}$ incorporation [36]. In fact, this lattice distortion, and the consequent increase in residual stresses can be observed in Fig. 8, which shows the evolution of the residual stresses with the $\mathrm{N}$ at.\%. From this graph it is clear that all coatings are in a high in-plane compressive stress states ranging from -3.2 down to $-8 \mathrm{GPa}$. The formation of the $\delta$-TiN phase, Fig. 3 , and consequently a more stable and energetically favourable structure is expected to be followed by stress relief, as is the case illustrated in Fig. 8, for the samples with the highest $\mathrm{N}$ contents.

Moreover and even though it is not detected by RBS (meaning that it should be less than 2 at.\%), it is to admit the existence of impurities such as those of oxygen that would influence hardness values [45-47]. The existence of some impurity atoms induces further local lattice strains, which inhibit the movement of dislocations, and thus strength, hardness and ductility are enhanced. This process is known as solid-solution hardening. A plot of hardness variation

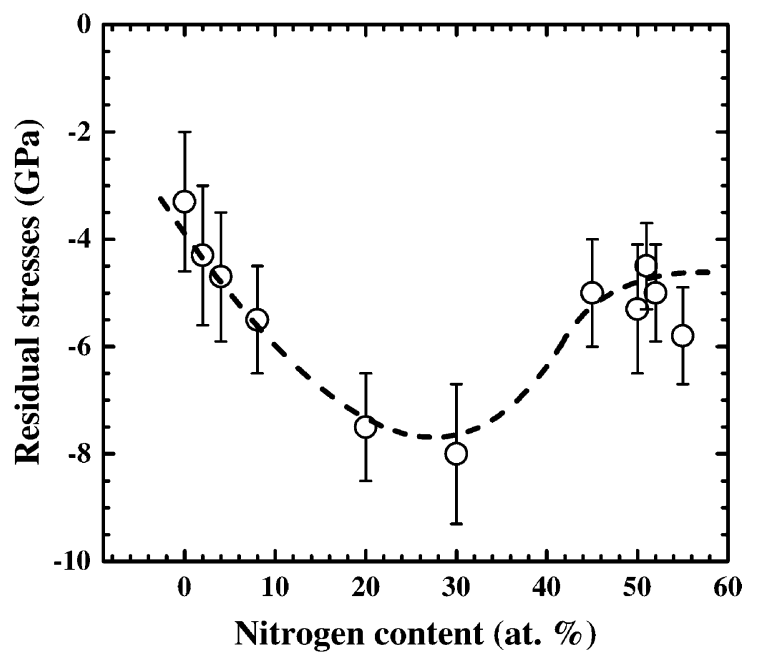

Fig. 8. Residual stresses in the $\operatorname{TiN}_{x}$ films as a function of the nitrogen content.

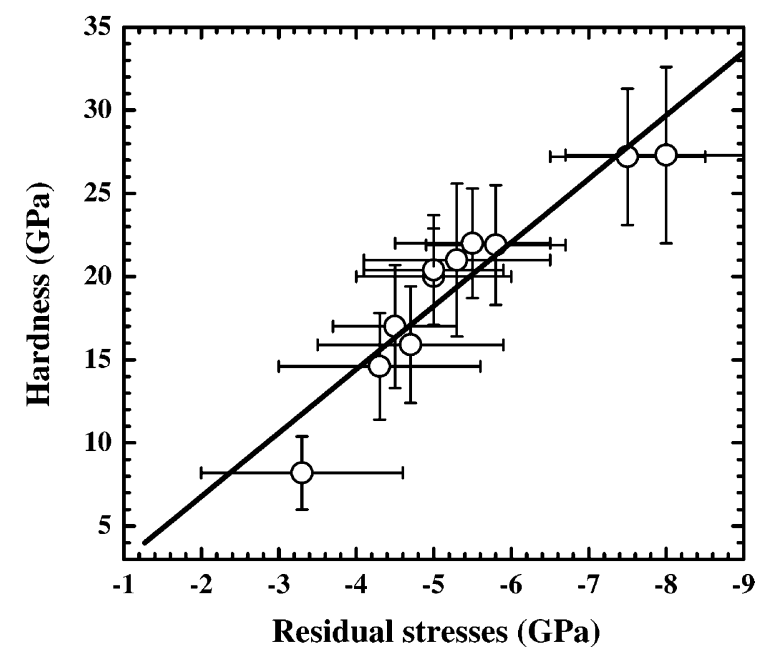

Fig. 9. Plot of hardness vs. residual stresses for the entire set of samples.

with the compressive stresses, Fig. 9, shows the existence of a relationship between compressive stresses and hardness. The hardness increases almost linearly with increasing stresses, showing that in fact not only phase formation and composition, but also the lattice distortions related to structural defects and correspondent increases in intrinsic stresses are determinant effects influencing the measured hardness of the coatings.

\section{Conclusions}

TiN films with different nitrogen contents were prepared in order to analyze the structural and mechanical features that occurred with the variation of this element content. With the increase in the flow rate of the gas, the nitrogen content first rises slowly from 0 to 8 at.\%. Further increasing the nitrogen flow ratio leads to a steeper increase of the coating nitrogen content up to 50 at.\%, which corresponds to the stoichiometric compound, TiN. For higher flows, the nitrogen content rises only slightly.

XRD diffraction patterns revealed the development of the hexagonal $\alpha$-Ti phase with strong [002] orientation for low nitrogen contents. For nitrogen contents between 20 and 30 at.\% the $\varepsilon-\mathrm{Ti}_{2} \mathrm{~N}$ phase appears with [200] orientation. Further increasing the nitrogen content, the $\delta$-TiN phase appears. SEM micrographs show a columnar-type structure lying in the transition zone between $\mathrm{T}$ and $\mathrm{I}$ zones of Thornton Model for all films, with a clear tendency for the thickening of the columns as the $\mathrm{N}$ content increases.

With increasing nitrogen content the films become harder, varying from approximately $8 \mathrm{GPa}$ for pure titanium up to $27 \mathrm{GPa}$ for a nitrogen content of 30 at.\%. The hardness remains constant with a value of approximately $20 \mathrm{GPa}$ within the range of 45 and 55 at.\% N. This behavior is mainly influenced by the two following contributions: (i) structure/composition (affected 
by the processing conditions) and; (ii) the lattice distortion and the correspondent increase in stresses. The two harder samples are those with the presence of the $\varepsilon-\mathrm{Ti}_{2} \mathrm{~N}$ phase, revealing a strong influence of crystalline structure in hardness behavior. The measurements of the electrical resistivity reproduce the phase behavior mentioned above. Interstitial impurities and phase composition are more relevant parameters than the microstructure itself for the behavior of the electrical resistivity.

Hardness also increases almost linearly with increasing stresses, revealing that the lattice distortions and the correspondent increases in intrinsic stresses are determinant for the hardening of the coatings.

\section{References}

[1] J.A. Thornton, J. Vac. Sci. Technol. 11 (1974) 666.

[2] H. Oechsner, J. Vac. Sci. Technol. A 16 (3) (1998) 1956.

[3] T. Takagi, Thin Solid Films 92 (1982) 1.

[4] P.J. Martin, J. Mater. Sci. 21 (1986) 1.

[5] D.N. Lee, J. Mater. Sci. 24 (1989) 4375.

[6] K.H. Müller, Phys. Rev. B 35 (15) (1987) 7906.

[7] M.J. Brett, J. Vac. Sci. Technol. A 6 (3) (1988) 1749.

[8] P. Meakin, P. Ramandal, L.M. Sander, R.C. Ball, Phys. Rev. A 34 (6) (1986) 5091

[9] S. Hong, E. Kim, B. Bae, K. No, S. Lim, S. Woo, et al., J. Vac. Sci. Technol. A 14 (5) (1996) 2721.

[10] A. Hamerich, R. Wunderlich, J. Muller, J. Vac. Sci. Technol. A 12 (5) (1994) 2873.

[11] A. Kinbara, E. Kusano, S. Baba, J. Vac. Sci. Technol. A 10 (4) (1992) 1483.

[12] F. Vaz, L. Rebouta, S. Ramos, M.F. da Silva, J.C. Soares, Surf. Coat Technol. 108-109 (1998) 236.

[13] M. Diserens, J. Patscheider, F. Lévy, Surf. Coat. Technol. 108-109 (1998) 241.

[14] S. Veprek, P. Nesládek, A. Niederhofer, F. Glatz, M. Jílek, M. Šíma, Surf. Coat. Technol. 108-109 (1998) 138.

[15] D.A. Glocker, S.I. Shah, Handbook of Thin Film Process Technology 2, IOP Publishing, Bristol and Philadelphia, 1995.

[16] H. Randhawa, Surf. Coat. Technol. 36 (1988) 829

[17] Y. Igasaki, H. Mitsuhashi, K. Azuma, T. Muto, Jpn. J. Appl. Phys. 17/1 (1978) 85 .
[18] J.-E. Sundgren, B.-O. Johansson, S.-E. Karlsson, Thin Solid Films 105 (1983) 353.

[19] J.-E. Sundgren, B.-O. Johansson, S.-E. Karlsson, Thin Solid Films 105 (1983) 367.

[20] J. Stanislav, J. Sikac, M. Cermak, Thin Solid Films 191 (1990) 255.

[21] F. Elstner, A. Ehrlich, H. Giegengack, H. Kupfer, F. Richter, J. Vac. Sci. Technol. A 12 (1994) 476.

[22] G. Berg, C. Friedrich, E. Broszeit, K.H. Kloos, Surf. Coat. Technol. $74-75$ (1995) 135

[23] M. Kawamura, Y. Abe, H. Yanagisawa, K. Sasaki, Thin Solid Films 287 (1996) 115.

[24] E. Ribeiro, A. Malczyk, S. Carvalho, L. Rebouta, J.V. Fernandes, E. Ailves, et al., Surf. Coat. Technol. 151-152 (2002) 515.

[25] B. Window, N. Savides, J. Vac. Sci. Technol. A 4 (1986) 196.

[26] N.P. Barradas, C. Jeynes, R.P. Webb, Appl. Phys. Lett. 71 (1997) 291.

[27] L.J. Van der Pauw, Philips Res. Rep. 13 (1958) 1.

[28] G.G. Stoney, Proc. Roy. Soc. Lond. A 82 1909, 172.

[29] F. Vaz, L. Rebouta, P. Goudeau, J.P. Rivière, M. Bodmann, G. Kleer, et al., Thin Solid Films 402 (2002) 195.

[30] M.F. Doerner, W.D. Nix, J. Mater. Res. 1 (1992) 397.

[31] G.M. Pharr, W.C. Oliver, MRS Bull. 177 (1992) 28

[32] I.N. Sneddon, Int. J. Eng. Sci. 3 (1965) 47.

[33] Z. Han, J. Tian, Q. Lai, X. Yu, G. Li, Surf. Coat. Technol. 162 (2003) 189 .

[34] A.I. Gusev, Phys.-Usp. 43 (1) (2000) 1.

[35] G.V. Samsonov, Handbook of Refractory Compounds, Plenum, New York, 1980.

[36] G.V. Kohlscheen, H.-R. Stock, P. Mayr, Surf. Coat. Technol. 120-121 (1999) 740.

[37] H.A. Wriedt, J.L. Murray, Bull. Alloy Phase Diagrams 8/4 (1987) 378

[38] K. Lu, M.L. Sui, R. Lück, Nanostruct. Mater. 4/4 (1994) 465.

[39] J.A. Thorton, Am. Revue Mater. Sci. 7 (1977) 239.

[40] J.A. Sue, Surf. Coat. Technol. 61 (1993) 115.

[41] H. Yoshihara, H. Mori, J. Vac. Sci. Technol. 16 (1979) 1007.

[42] A. Matthews, D.G. Teer, Thin Solid Films 73 (1980) 367

[43] A.K. Suri, R. Nimmagadda, J. Amiguet, Thin Solid Films 72 (1980) 529 .

[44] V. Poulek, J. Musil, V. Valvoda, R. Cerny, J. Phys. D: Appl. Phys. 21 (1988) 1657

[45] W.D. Callister Jr, Materials Science and Engineering. An Introduction, John Wiley \& Sons, Inc, 1985.

[46] P. Karvankova, M.G.J. Veprek-Heijman, O. Zindulka, A. Bergmaier, S. Veprek, Surf. Coat. Technol. 163-164 (2003) 149.

[47] J.E. Lowther, MRS Bull. (3) (2003) 189. 